Article

\title{
Assessing the Opportunities and Challenges of Green Finance in Italy: An Analysis of the Biomass Production Sector
}

\author{
Pasquale Marcello Falcone ${ }^{1, *(\mathbb{D})}$ and Edgardo Sica ${ }^{2}$ (D) \\ 1 Bioeconomy in Transition Research Group, IdEA, Unitelma Sapienza-University of Rome, Viale Regina \\ Elena, 291, 00161 Roma, Italy \\ 2 Department of Economics, University of Foggia, Largo Papa Giovanni Paolo II, 71121 Foggia, Italy; \\ edgardo.sica@unifg.it \\ * Correspondence: pasquale.falcone@unitelmasapienza.it
}

Received: 19 December 2018; Accepted: 16 January 2019; Published: 19 January 2019

\begin{abstract}
The present paper provides empirical evidence of the opportunities and challenges surrounding green finance (GF), looking at the financial issues that might prevent the investment decisions of green companies. To this end, we explore the case of Italian biomass producers by means of a discourse analysis supported by a survey administered to a pool of experts. Although our findings suggest that GF provides an opportunity for achieving environmentally sustainable innovation pathways, experts recognize that it does not actually prevent biomass producers from facing institutional and financial criticalities in funding their investment projects. Such criticalities include: uncertainty about government policies, the minimal involvement of financial suppliers in the biomass sector, the short-term orientation of financial instruments and the limited knowledge of financing options and technical expertise within companies. The results indicate that effective policy interventions should ensure that objectives are orientated towards the long term with the aim of reducing the risks perceived by financial institutions in funding biomass producers.
\end{abstract}

Keywords: green finance; discourse analysis; biomass production; subsides; Italy

\section{Introduction}

Achieving the goal of a circular economy depends on the creation of an economy where the "end-of-life" concept is replaced by the option of getting rid of waste through the superior design of materials, products, systems, and business models [1]. Along with this, the circular economy can be conceived as an economic model founded on the essential goal of reducing emissions by recurring to the use of green sources of energy. From this perspective, renewable energy sources (RES) represent a driving and shaping element towards the clean global economy of the future since they allow to replace fossil fuels which are blamed for warming the planet. In the framework of RES, in recent years biomass has been increasingly receiving strong scientific attention as a sustainable energy source, mainly due to its environmental, economic, and social advantages in terms of large availability within countries, versatility in energy production, job creation in the biomass-related activities, and waste reduction consistently with the aims of a circular economy [2,3]. In particular, wood and other solid biomass are extensively used in conventional thermal generation power plants and are expected to increase their contribution to the production of energy supply in the coming years [4]. However, despite the aforementioned strengths, biomass also exhibits a number of weaknesses, mainly due to the larger amount of $\mathrm{CO}_{2}$ emitted compared to other RES as well as higher costs in comparison to alternatives [5]. As for the photovoltaic, this makes the biomass sector generally dependent upon mandates and subsidies with the consequence that, in absence of a government support, a financial 
gap in the possibility of producing biomass may arise [6]. In this framework, therefore, the "green finance" (GF) - the financing of investments that provide environmental benefits in the broader context of environmentally sustainable development $[7,8]$ —may significantly contribute to guarantee capital flow in the biomass sector as well as to enhance the sustainability of the overall financial system. The promising benefits of GF have not yet produced relevant effects within the financial mainstream due mainly to issues related to: (i) the short-term orientation of the dominant financial sector [9]; and (ii) limited access to capital for green companies, especially small and medium enterprises [10]. These issues can lead to the inadequate flow of capital necessary for green investment strategies in the biomass production, hindering opportunities for a systemic change to occur. In this context, increasing the involvement of banks, financial regulators and grassroots organizations in integrating environmental and social elements within the dominant financial system is crucial for transitioning to a low carbon economy [11].

Starting from these premises, in the present paper we complement the growing interest in GF by filling the gap in the literature pertaining to empirical research on the financial constraints faced by green companies. To this end, we explore the case of Italian biomass producers by means of a discourse analysis supported by a direct measure of financial criticalities obtained by a survey administered to a pool of experts in biomass production. In particular, we aim at addressing the following two research questions: [RQ1] "Which discourses surround GF?" and [RQ2] "What opportunities and criticalities could GF provide to the biomass production sector?" To this purpose, we employ a two-fold methodological approach. First, using discourse analysis, we study the language used in the GF debate, deriving the most relevant discourses, the "ideas, concepts and categories through which meaning is given to social and physical phenomena, and which is produced and reproduced through an identifiable set of practices" [12] (p. 67). To this end, we investigate the Italian case, which represents a relevant framework for our analysis since, in recent years, the Italian financial system has been characterized by scandals and bankruptcies, making it an arena of extensive discussion and criticism at the socio-political level. Second, we employ survey-based research with a pool of experts in the field of biomass production, in order to deepen our understanding of financial criticalities and their related impact on firms' investment decisions, focusing on the Italian biomass production sector.

The remainder of the paper is organized as follows: Section 2 explores the theoretical framework; Section 3 discusses the case study and methodological approach; Section 4 presents the results and discusses the policy implications; Section 5 concludes the article.

\section{Theoretical Framework}

The transition towards a low carbon and climate resilient economy requires the investment of significant economic resources in "green" sectors [13]. The UNEP [14] estimates that the annual investment necessary to deliver a green economy over the 2010-2050 period will be approximately $2 \%$ of global GDP. One of the most relevant features of environmentally sustainable investments (particularly in clean energy sources and green technologies) is the inclusion of multiple technologies at different stages of maturity; each of these technologies may require a different type of financing [15]. Moreover, the funding requirements for a sustainability transition may significantly exceed the capability of the public sector, demanding substantial involvement from private sources of financing and more tailored use of existing funds [16]. From this perspective, GF plays a critical role in fostering firms' environmentally sustainable investments, supporting countries to reduce emissions, de-carbonize economies and adapt to the consequences of climate change [17].

Following Höhne et al. [18], GF can be defined as the whole of "financial investments flowing into sustainable development projects and initiatives, environmental products, and policies that encourage the development of a more sustainable economy." Accordingly, GF is not limited to climate finance (i.e. the set of financial tools specifically aimed at mitigating greenhouse gas emissions and adapting to climate change), but includes all financial products and services aimed at a wider range of environmental objectives, such as industrial pollution control and water, sanitation and biodiversity 
protection. Moreover, it comprises the "operational" costs of green investment, costs that are generally not included within the definition of green investment (e.g. project preparation and land acquisition costs) but can pose relevant financing challenges [19].

GF encompasses numerous financial instruments, such as public funds, venture capital, business angels, project financing, equity, debt, pension funds and green infrastructure bonds. Many are tailored to a specific developmental stage of a green project: venture capital is employed with unproven and untested technologies; project financing is used for mature technologies and green infrastructure bonds are used in the latter stages of a project (e.g. operational refinancing). A key feature of all GF instruments is that they make investment and lending decisions according to environmental screening and risk assessment with the aim of meeting environmental sustainability standards [20]. In other words, GF takes environmental factors into account throughout the investment and lending decision making, ex-post monitoring and risk management processes [21]. In this regard, investors should be driven to green invest for various reasons, including ethical considerations, advantageous return profiles, legal or regulatory constraints and improved investor reputation [15].

An increasing body of literature $[17,22]$ is devoted to assessing GF effectiveness by investigating the way in which smaller amounts of finance can be used to enable a sustainability transition. In this framework, Chaum et al. [23] suggest that GF effectiveness depends on different factors, including the efficiency of the green project, the sustainability of the funded investment and the transparency of the decision making processes. However, compared to other types of investment projects, green projects exhibit a number of case-specific characteristics. First, most produce cash flows and returns in the long term, only, despite the large upfront investments required [24]. Second, they often show an unattractive risk/return profile due to the relative immaturity of green industries; this increases the perception of risk from investors associated with the future evolution of the technologies and markets [13]. Although some green technologies are developing quickly, they are still in the early stages of market penetration, and this significantly raises the market volatility associated with this kind of investment. Additionally, the risks for investors are increased by market distortions due to the maturity of traditional high-emission technologies. Third, green investments are perceived as strongly dependent upon public support, which is often unpredictable and not transparent. Consequently, political instability and the uncertainty of the regulatory and policy environment represent an additional risk for investors [25]. All of these features significantly contribute to reducing the attractiveness of green investments to many investors, generating a financial gap and reducing the overall funds available for green projects, especially in small and medium enterprises [26]. In other words, according to the financial literature, the capital market frictions that arise from green investments increase the cost of external capital for enterprises that try to finance their investment projects primarily through internal funds [27]. Therefore, any shortage of internal financial resources makes companies "financially constrained," and this prevents them from funding their desired investments [28].

However, the financial literature lacks empirical studies addressing the investment decisions of green companies, specifically. To the best of our knowledge, only Sica [29] has empirically analyzed the financial constraints of eco-innovative companies, finding that the financial criticalities of green enterprises may significantly reduce their likelihood to engage in investment projects. In contrast, a plethora of studies have investigated the financial problems faced by companies, but with no specific focus on environmentally sustainable decisions. In this framework, while the existence of a link between a company's investment, its innovative performance and the existence of financial criticalities appears well rooted in the literature, related empirical investigations have produced unclear results, which mostly seem affected by the proxy employed to measure financial constraints. In particular, when these have been proxied by means of an indirect measure obtained from secondary data (especially when amount of cash flow has been used as a proxy of internal funds available), the results have been quite mixed. Indeed, some studies [30,31] have suggested significant cash flow sensitivity in companies' investment decisions, while others [32,33] have provided evidence of the opposite. In contrast, when financial criticalities have been investigated by employing a 
direct measure (i.e., ad hoc surveys designed to collect companies' views on barriers to funding their investment projects), the results have seemed to univocally support the existence of financial constraints hindering firms' investment behavior. This is true, for instance, for the empirical studies carried out by Mancusi and Vezzulli [34], Mina et al. [35], Stockdale [36], Silva and Carreira [37], Campello et al. [38] Savignac [28] and Mohnen et al. [39]. In this article, therefore, we try to fill the gap in the empirical literature about the financial constraints by employing a direct measure of financial constraints gathered by a survey administered to a pool of experts in biomass production.

\section{Materials and Methods}

\subsection{Case Study}

In this study we analyze the case of the Italian agroforestry biomass sector by investigating the criticalities that affect the investment decisions of its producers. Agroforestry biomass consists of agricultural, agro-industrial and forest residues (i.e. any source of solid biomass, excluding renewable waste). In particular, the country is characterized by a huge amount of agricultural residue from herbaceous and woody crops, although only a small percentage of this potential is actually converted into energy [40]. Indeed, most of this biomass is not easily reachable, comes from numerous small farms and is often employed for other ends, for instance animal feed, fertilizer and household combustion [41]. Similarly, residues from agro-industrial sectors are frequently used for energy production at the same sites at which they are produced.

Moreover, uncertainty about the profitability of biomass production has mean that the market has not always been able to supply an optimal level of biomass [42]. As a result, there has been a generally recognized need for public intervention to correct for market imperfections. Thus, in Italy, biomass production for energy purposes has been financially supported by a number of public interventions in the last decade, such as the 2007 and 2008 Financial Laws and the 2007-2013 Programmes for Rural Development. More specifically, the 2007 Financial Law established that the production and sale of electricity and heat from renewable agroforestry plants carried out by farmers constitute activities producing agricultural income, provided that the raw materials come from the property, whereas the 2008 Financial Law established that the production of electricity from plants fueled by biomass and biogas produced from agricultural activities, livestock and the forestry sector are entitled to Green Certificates. Finally, the 2007-2013 Programmes for Rural Development allowed direct financing for the purchase and/or construction of plants not exceeding $1 \mathrm{MW}$ for the production of electricity and heat from biomass. Additionally, in order to achieve a low carbon economy and to comply with the objectives of the Investment Plan for Europe, the European Commission has encouraged Member States to at least double their use of innovative financial instruments in key investment areas under the 2014-2020 European Structural and Investment (ESI) funds scheme [43,44]. In this framework, energy-related allocations to Italy are among the highest in the EU, although the amount tailored to biomass production remains very limited compared to other RES.

In particular, within the ESI thematic objective no. 4 ("Supporting the shift towards a low carbon economy"), by 2020 Italy plans to benefit from 3245.8 million euros, in terms of grants $(87.5 \%)$, repayable grants $(4.2 \%)$, loans $(6 \%)$, guarantees $(1.4 \%)$, equity/venture capital $(0.8 \%)$, and other categories of funding $(0.1 \%)$ [45]. It is worth noting that the ESI funds are affected by the challenges common to any financial instrument, but involve further problems, such as engaging with new stakeholders, technical feasibility and the need to increase the acceptability of repayable finance in this area. Moreover, financial intermediaries have faced some difficulties in implementing financial instruments set by the ESI funds due to changes in the regulatory framework between programming periods. In this framework, investigating the criticalities that can hinder the investment decisions of agroindustry biomass producers can therefore represent a relevant and worthwhile task. 


\subsection{Methodology}

Looking at the aforementioned theoretical framework, this study tries to address the discussion using a narrative perspective (i.e. discourse analysis) that recognizes discursive interaction as a valuable tool to ascertain opinions, ideas and facts concerning the GF debate in Italy. The concept of discourse has received growing interest in the academic community in the social sciences. Hajer [13], in his seminal paper on the influence of "acid rain" debate on environmental concerns, defines discourse as a set of ideas, thoughts and perspectives that shape the overall meaning of physical phenomena by framing storylines. As stated by Hajer, "storylines are the medium through which actors try to convince others of their positions, suggest certain practices, and criticize alternatives" [13] (p. 71). Therefore, actors strive to frame their perspectives using competing storylines that are developed to relate the content and context of an innovation in order to build consensus [46]. Investigating the current debate surrounding the greening of the financial system might reveal the most prominent storylines used to convince public opinion and policy makers with respect to their strategic orientations towards sector development.

With the aim of answering our research questions, we first isolated the key emerging storylines within the sustainability debate among financial actors. Subsequently, building on the identified storylines and using a survey-based methodology, we sought to deepen our understanding about challenges and criticalities faced by biomass producers in their green investments decisions. Thus, the research employed a two-step analysis. In the first step, we carried out a deep literature review starting in the Scopus database (www.scopus.com) to identify published scientific articles on the topic. In this respect, we paired some anchor keywords (i.e., bio*, green*, and sustainab*) with other search strings (i.e. "finance", "biomass producers," "climate finance," etc.) to retrieve pertinent documents in a timeframe ranging from 2010 to 2017. With the aim of integrating this exercise with additional information from the so-called "grey literature" [47] (i.e., technical reports, fora, guidelines, websites, etc.), we employed the Google search engine. This analysis enabled us to select more than 500 documents on GF. Successively, through an inspection process of selected documents, a smaller list of contributions was deemed pertinent for our analysis with a higher prevalence of the grey literature. Chosen articles were then examined employing the QDAMiner 5.0 software package [48], which enabled us to perform a qualitative analysis of related narratives that best depicted actors' perceptions of the topic under investigation.

The second step of our analysis intended to determine the extent to which the storylines revealed in the first step were perceived reliable in the process of securing GF. To this end, employing a survey-based research methodology, we exploited experts' knowledge and considerations to identify baseline financial issues regarding firms' decisions to invest in biomass production in Italy. A preliminary list of actors was identified from the Italian Association Biomass database (AIEL), which includes companies operating along the wood-energy chain from producers of wood biofuels (wood, wood chips, pellets) to producers of technologies to transform these biofuels into heat and energy (stoves, inserts chimney, boilers, cogeneration groups. The association has more of 500 effective members covering different categories: producers and distributors of firewood, pellets and chips; technology manufacturers (heating and cogeneration systems); designers, installers and maintenance technicians; energy service company, agricultural and forestry companies, component manufacturers, consultancy companies, institutions and trade associations. Such database provides detailed information on the typology of actors (i.e. producer, supplier, distributor, academia, etc.), their involvement in biomass sector (i.e. forestry, consultancy, trade association, etc.) and related expertise.

In a further stage, drawing on information gathered on websites, technical reports and blogs, we refined the list by considering only actors with long-term involvement (i.e. more than 10 years) specifically in the field under investigation. This allowed us to focus on a much smaller number of members (i.e. 30) which have been contacted for the interview with the intention of representing the range of actors involved in biomass production (see Table 1). The names and identifying information of the seven interviewees were anonymized for privacy reasons. Although it might appear a limited 
number of interviews to conduct a solid analysis, given the limited number of actors with a specific long term involvement in biomass production sector, our sample seems to be adequate for embedding different perspectives and experiences.

Table 1. Characterization of respondents.

\begin{tabular}{ccc}
\hline Category & Involvement & Expertise \\
\hline R1. Company & Forest management & Afforestation, reforestation, harvesting, etc. \\
\hline R2. Company & Forest consulting & $\begin{array}{c}\text { Evaluating forest resources, planning the sustainable use of } \\
\text { biomass, understanding regeneration potential after wildfire. }\end{array}$ \\
\hline R3. Company & Woodchips production & $\begin{array}{c}\text { First processing of wood for the production of wood chips for } \\
\text { biomass solid fuel. }\end{array}$ \\
R4. Academia & $\begin{array}{c}\text { Research, projects and thematic } \\
\text { activities in the bio-economy }\end{array}$ & $\begin{array}{c}\text { Analysis of the use and protection of natural resources, their } \\
\text { sustainable use in agriculture, environmental and agricultural } \\
\text { policies and decision making methods. }\end{array}$ \\
\hline R5. Journalist and blogger & Informative services & $\begin{array}{c}\text { Long-term involvement within various sections of the } \\
\text { bio-economy supply chain, from feedstock to intermediates, } \\
\text { downstream buyers and suppliers. }\end{array}$ \\
\hline R6. Trade association & $\begin{array}{c}\text { Representing interests along the } \\
\text { wood energy supply chain }\end{array}$ & $\begin{array}{c}\text { Technical skills of sustainability practices affecting } \\
\text { sector productivity. }\end{array}$ \\
\hline R7. Policy maker & Agricultural and forestry policies & Source: Authors' elaboration.
\end{tabular}

The survey was based on seven semi-structured interviews conducted by telephone over the period of April to May 2018, lasting approximately 30 to 50 minutes. Questions adhered to each respondent's specific expertise, with some common key questions aimed at assessing the actual relevance of internal and external barriers to securing green financing, as emerged in the discourse analysis. Finally, data arising from each interview were triangulated, both by comparing the opinions and arguments presented in one interview with those of others, as well as relating interview data to the literature in order to enhance the credibility of the investigation.

\section{Results}

\subsection{Discourse Analysis}

The semantic perspectives identified in the discourse analysis broadly rest upon two distinctive but strictly related storylines concerning the GF debate. In particular, actors struggle towards content-related discourses to build storylines that recognize, on the one hand, "GF as an opportunity for sustainable development and innovation" (S1) and, on the other, the "presence of institutional and financial barriers hindering green investment strategies" (S2).

The first storyline (S1) is supported by dedicated actors who are actively involved in green investments (e.g. ethical banks, monitoring and support service providers, etc.) who innovatively relate their claims about content (e.g. GF fosters sustainable development) to the analytical context (e.g. economic downturn, EU policy priorities, environmental awareness, etc.) (see Figure 1). 


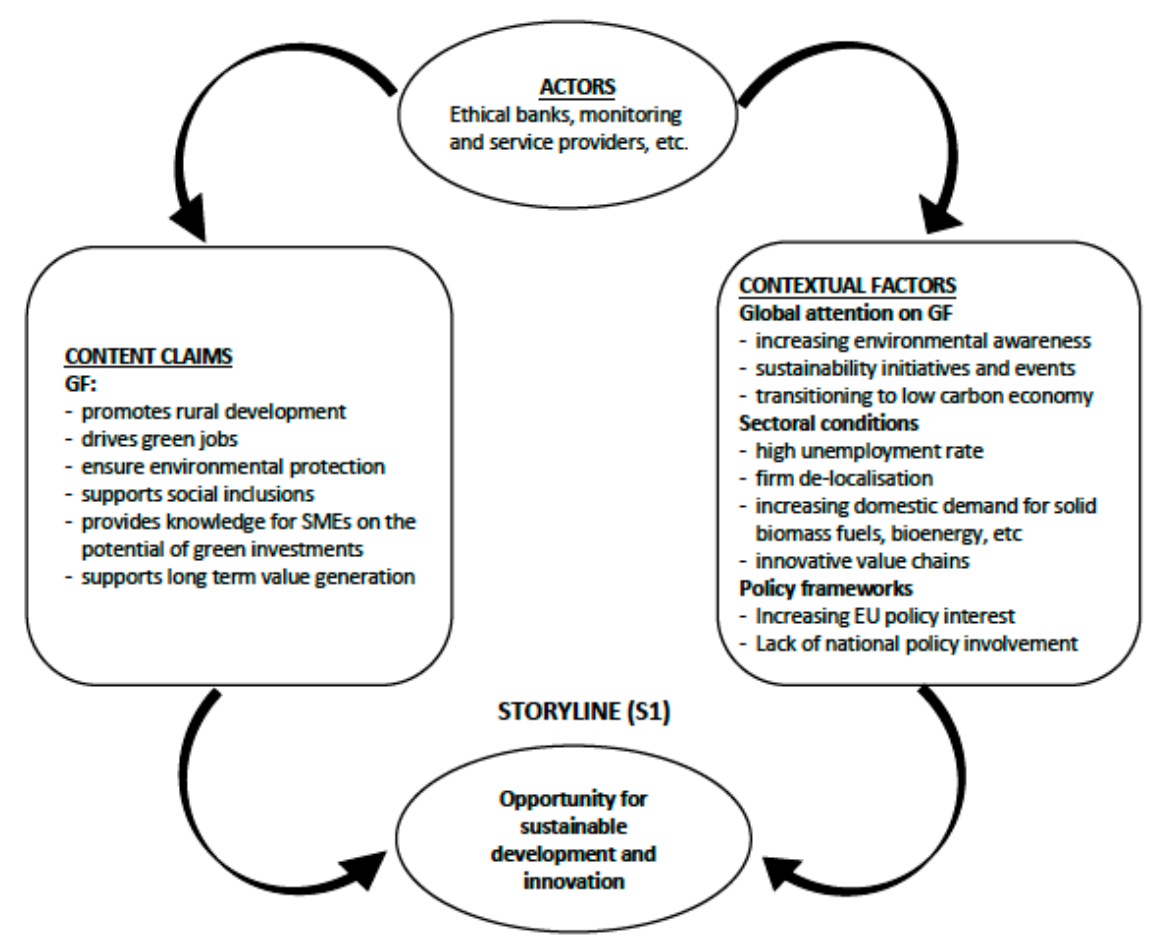

Figure 1. Process of storyline formation (S1).

Figure 1 elucidates the processes of the first storyline formation. More specifically, actors express ideas and claims concerning the content of the analysis (i.e. GF) and relate these perspectives to the real context in which they operate. The legitimization of the first storyline is based upon the potential capacity of GF to promote rural development, environmental protection, green jobs and, thus, social inclusion [49]. In this perspective, sustainability criteria (i.e. criteria developed to finance small and medium sized projects, giving priority to energy saving, green innovations and the creation of local supply chains - e.g. "Progetto Energia," Banca Popolare Etica) are considered the appropriate main priority of the financial sector. Funded companies are thus thought to be organizations whose mission must be directed towards a responsible profit, meeting the social and environmental aspects identified within the sustainable development path [50]. It seems that the actors supporting S1 link such claims to the general context (e.g. the high unemployment rate, innovative value chains) in order to build legitimacy. Thus, GF might represent a possible way out of the adverse economic conditions that have affected the country during the last decade, by funding firms' aptitude to compete and innovate in the bio-economy [51].

In response, a rival storyline (S2) is advanced by a broad set of actors (e.g. academics, policy makers, trade associations, etc.) who emphasize the potential presence of adverse circumstances (internal and external to the business seeking green funding) characterizing the increase of GF in Italy (see Figure 2). 


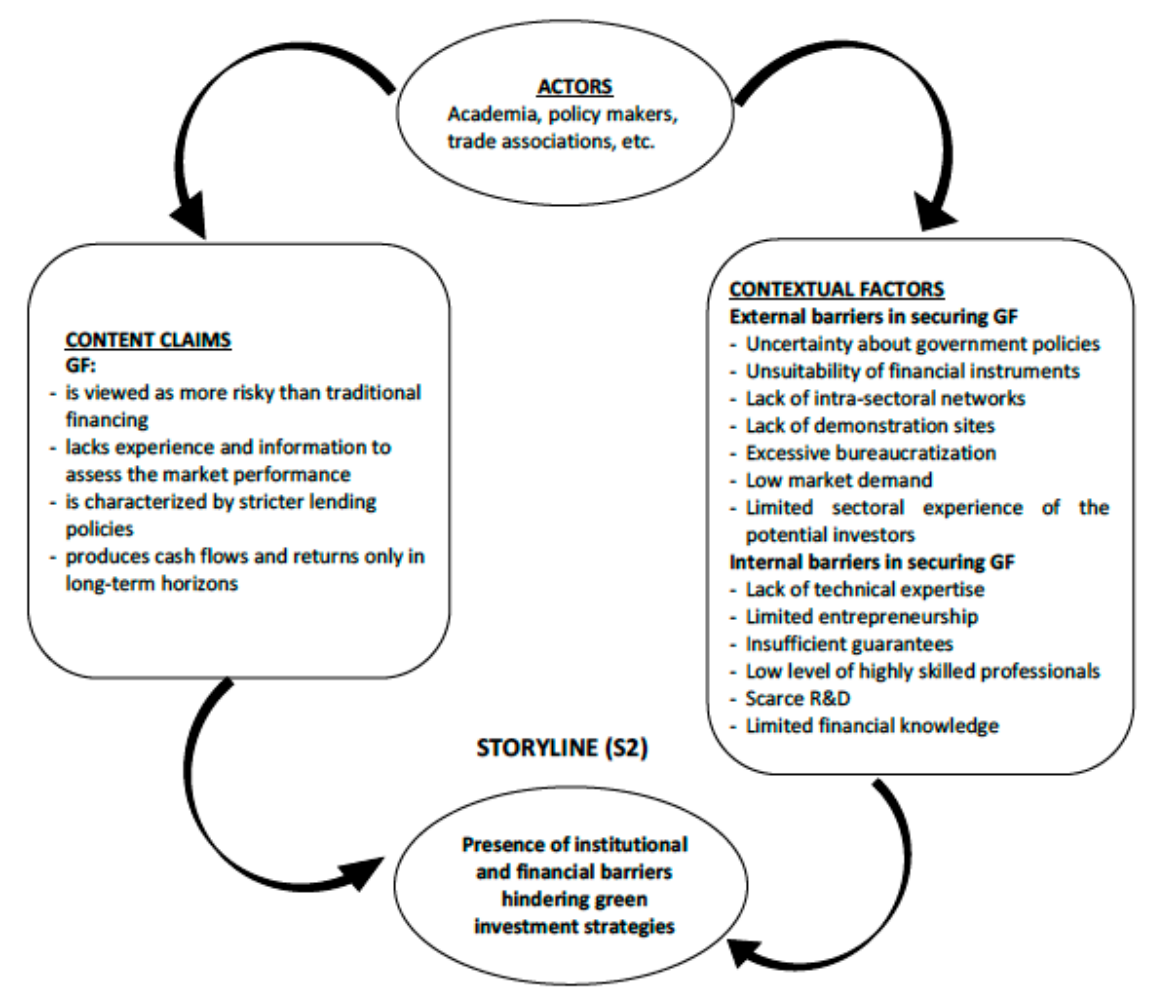

Figure 2. Process of storyline formation (S2).

One of the main reasons for the sustainable finance gap is the short-termism of the dominant financial markets. In particular, promoting sustainability by funding environmentally friendly projects often requires large upfront investments leading to cash flows and returns only in the long term [24]. This is due to adverse selection, whereby financial intermediators often miss relevant information to adequately appreciate the technical and market performance of new green projects [20]. This, in turn, makes GF more risky than traditional financing, thereby constraining the credit available for interested firms. Actors supporting the second storyline intuitively connect GF to these contextual factors characterizing small and medium enterprises, both externally (e.g. with respect to the limited sectoral experience of potential investors) and internally (e.g. with respect to limited entrepreneurship) [7].

\subsection{Results from the Questionnaire}

The interviews seem to unequivocally support S1 ("GF represents an opportunity for achieving sustainable development and innovation pathways"). According to the experts, financial actors have a crucial role to play in achieving the transition to new environmentally sustainable pathways. Due to their role as capital flow facilitators and innovation financiers, they can significantly contribute to financing major environmental policy shifts. GF, in particular, is perceived by all respondents as a pivotal way for green companies to get funded and for Italy's biomass production sector to expand. More specifically, the experts from the three companies (R1, R2 and R3) believe that GF tools allow biomass producers to benefit from easier access to funding than other types of investment. Moreover, they hold that the possibility to invest in green projects is associated with an increase in job opportunities in the biomass sector, enabling a win-win solution whereby both environmental protection and long-term value are guaranteed. The opportunities emerging from our empirical analysis seem to fall broadly in line with the recent literature. In particular, the relevance of GF for financing green companies is a key finding of the Deutsche Bundesbank [52], which recognized the upcoming transition to a low carbon economy as a promising long-term business opportunity. Similarly, the easier access to green funding relative to other types of investment supports the results achieved by Clark et al. [53] on the progress and potential of private finance for climate 
and sustainable development. Finally, the contribution of GF to increasing job opportunities is in line with the findings attained by Bowen and Kuralbayeva [54]. However, despite the recognized importance of GF for a sustainable transition to occur, biomass producers face a number of barriers at different levels (institutional, financial, etc.) and are even financially constrained, providing evidence for S2 ("The presence of institutional and financial barriers seriously hinder the securing of green investment decisions").

At an institutional level, four out of seven interviewees declared that uncertainty about government policies represents the most relevant barrier to investment in the Italian biomass sector. According to the respondents, policies supporting biomass production should be "certain," "long-term oriented," and surrounded by a "clearly established" regulatory framework. In particular, one respondent (i.e. R7) declared that the government policies are necessary to correct for market failures arising from the subsidies that are still provided to traditional fuel producers, which, in the financers' viewpoint, make investments in the biomass sector uncompetitive. Moreover, R4 recognized a further institutional barrier in the lack of any policy intervention to support the commercialization of new technologies in the biomass sector.

At a financial level, six out of seven respondents believed that the most relevant barrier surrounding biomass production in Italy is represented by the potential financial suppliers who are not sufficiently engaged with the sector. Another recognized criticality is the different expected returns of financial suppliers relative to the companies' business goals, followed by the type of finance, which is often not tailored to small-scale investment needs. These problems also relate to the different time horizons of short-term investment and risk performance management versus long-term environmental risk. Indeed, according to the interviewees, the short-term orientation of most financial tools does not match the financial needs of biomass producers, who normally look for long-term sources of finance. This implies higher risk and liquidity premiums, making the projects less viable from a finance perspective. Moreover, R5 and R6 believe that the lack of knowledge of financing options and of technical expertise, as perceived by the perspective financiers, represent two additional barriers to companies seeking funding.

Overall, our results seem to support the narratives surrounding the financial framing conditions that characterize Italian biomass production summed up in the two key storylines, S1 and S2. In other words, the pool of experts confirmed the relevance of GF as an opportunity for achieving environmentally sustainable and innovation pathways, but, at the same time, recognized that this does not prevent biomass producers from facing institutional and financial barriers in funding their investment projects that can lead them to be financially constrained.

While - to the best of our knowledge-there is a lack of empirical research on the financial constraints of green companies, the above results seem to agree with studies that have investigated, from different perspectives, the financial framework of green investment. In particular, our findings confirm the results obtained by Rosillo-Calle and Woods [55], who stressed the relevance of capital and, above all, financial constraints surrounding the biomass sector in hindering the production of forestry energy crops at a large scale. Similarly, the problem of the short-term orientation of financial tools not matching the long-term investment needs of companies seems to align with the outcomes of Falcone et al. [9], who found evidence of a short-term orientation of the GF sector due mainly to adverse selection in financial markets. Moreover, the different expectations between financial suppliers and companies about possible investment results is consistent with the findings of Guilhermino et al. [56], who revealed that the use of forest biomass residues for bioenergy purposes may be financially unattractive due to low expected profitability, which negatively affected financers' decisions. Finally, the finding of the relevance of knowledge about financing options and the technical aspects of production supports the findings achieved by Mazzucato and Semieniuk [57] in their study of the way in which financial actors differ in their decisions about funding the green sector. 


\subsection{Discussion and Policy Implications}

Turning back to our first research question (RQ1), our findings show that the discourses surrounding GF give rise to two rival storylines emphasizing, respectively, the opportunity for sustainable development and firm innovation and the presence of institutional and financial barriers hindering green investment. Looking at our second research question (RQ2), the results allow us to identify opportunities and criticalities affecting the biomass production sector, which are summarized in Table 2.

Table 2. Overview of opportunities and criticalities affecting GF in Italy.

\begin{tabular}{|c|c|}
\hline OPPORTUNITIES & CRITICALITIES \\
\hline $\begin{array}{l}\text { - Pivotal way for green companies to get funded and for the } \\
\text { biomass production sector to expand. }\end{array}$ & $\begin{array}{l}\text { Institutional } \\
\text { - Uncertainty about government policies. } \\
\text { - Lack of policy intervention to support the }\end{array}$ \\
\hline $\begin{array}{l}\text { - Easier access to funding than other types of investment for } \\
\text { rural development. }\end{array}$ & 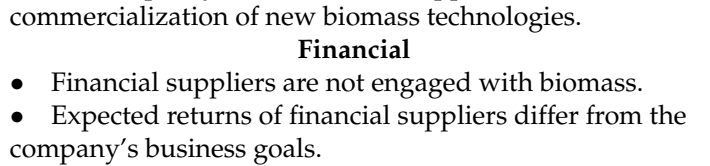 \\
\hline - Increase in job opportunities in the entire biomass sector. & $\begin{array}{l}\text { - Short-term orientation of financial tools does not match } \\
\text { long-term investment needs. } \\
\text { - Lack of knowledge of financing options and of technical } \\
\text { expertise in biomass producers, as perceived by financiers. }\end{array}$ \\
\hline
\end{tabular}

Source: authors' elaboration.

Our results provide a comprehensive overview of the role of GF in the biomass production sector, offering useful insights for policy making. With regard to institutional criticalities, a tailored policy intervention should be implemented with the aim of ensuring a long-term orientation of objectives and a high degree of certainty and clarity of the regulatory framework. This could limit market distortions and make biomass more competitive with other energy sources, thereby reducing the risks perceived by financiers in funding biomass producers. Moreover, with the aim of accounting for financial criticalities, policy actions should be directed to increase the economic and financial sustainability of environmental projects. This could be pursued by fostering stronger collaboration among stakeholders involved in biomass production in order to speed up green-oriented financial initiatives and their related dissemination. At the same time, policy makers should encourage the long-term orientation of GF instruments by means of the active involvement of national institutional actors, who can play a key role in de-risking the private sector, leading the way to new technological opportunities [58]. Furthermore, in order to deal with the limited knowledge of financing options and technical expertise within companies, entrepreneurship programs tailored to GF, training courses for professionals and workers and a general reduction in bureaucratic administration could be implemented [59]. Finally, policy intervention could also be directed towards the exploitation of GF opportunities for the biomass production sector. For example, following the recent US experience (i.e., SIPPRA - Social Impact Partnerships to Pay for Results Act.), national legislation could unlock substantial new funding for social, health and environmental programs. This has already been achieved by the Environmental Impact Bonds, which rely upon private capital to achieve effective environmental goals and repay investors in a "pay for success transaction for outcomes" scheme. This policy strategy is part of a broader and growing trend towards evidence-based policy making.

\section{Conclusions}

To successfully manage societal challenges (i.e. climate change, resource depletion, etc.) that involve a sustainability transition, the implementation of a green agenda incorporating GF is needed at both national and international levels. This requires open and sustained debate in each country about the opportunities, bottlenecks and priorities of GF for national action. In this framework, the present paper has analyzed the opportunities and criticalities affecting GF by investigating the extent to which 
they might hinder the investment decisions of Italian agroforestry biomass producers. To this end, we carried out a two-step research design. First, by means of discourse analysis, we identified the relevant storylines surrounding the GF debate in Italy. Then, through semi-structured interviews with a pool of biomass experts, we assessed the extent to which these storylines are perceived as reliable in the process of securing GF. Our findings show that GF actors seem to draw together content-related claims to form storylines that consider GF an opportunity for sustainable development and innovation (S1); however, they also recognize the presence of institutional and financial barriers hindering companies' green investment strategies (S2). According to the interviewees, both storylines are reliable and provide a comprehensive overview of current processes of securing GF in Italy. More specifically, experts believe that, in facilitating the financing of green investments, GF provides a win-win solution wherein both environmental protection and long-term value (in terms of companies' innovative performance, increased job opportunities, social inclusion, etc.) are guaranteed. However, experts also recognize the existence of several institutional and financial criticalities that hamper opportunities for companies' green projects to receive funding. In particular: (i) uncertainty about government policies; (ii) limited policy support for the commercialization of new technologies; (iii) scarce involvement of financial suppliers in the biomass sector; (iv) different expected returns of financial suppliers compared to companies' business goals; (v) finance not being tailored to small-scale investment needs; (vi) the short-term orientation of financial instruments; and (vii) limited knowledge of financing options and technical expertise within companies. It is worth noting that criticalities (i) and (ii) relate to the institutional context, criticalities (iii) through (vi) relate to the current GF system and criticality (vii) relates to companies' internal characteristics.

The main limitation of this study concerns the qualitative characterization of the empirical analysis. While our two-step methodological approach represents a valuable tool for policy design, it may be unsuitable for policy engineering, since it does not allow for quantitative assessment of the policies that should be implemented.

Our methodological technique and findings provide insights for further investigations aimed at exploring the criticalities surrounding GF from different perspectives, for instance, from the perspectives of other sectors within the green industry at different geographical dimensions.

Author Contributions: P.M.F. and E.S. conceived and designed the study methodology and contributed to the primary share of the article writing. P.M.F. wrote the introduction and methodology. E.S. wrote the theoretical framework and the case study. Both authors contributed to write results and conclusions.

Conflicts of Interest: The authors declare no conflict of interest.

\section{References}

1. Tukker, A. Product services for a resource-efficient and circular economy-A review. J. Clean. Prod. 2015, 97, 76-91. [CrossRef]

2. Bracco, S.; Calicioglu, O.; Gomez San Juan, M.; Flammini, A. Assessing the Contribution of Bioeconomy to the Total Economy: A Review of National Frameworks. Sustainability 2018, 10, 1698. [CrossRef]

3. European Commission. Renewable Energy Progress Report; European Commission: Brussels, Belgium, 2017.

4. Eurostat. Renewable Energy Statistics. 2017. Available online: http://ec.europa.eu/eurostat/statisticsexplained/index.php/Renewable_energy_statistics (accessed on 18 June 2018).

5. Olofsson, J.; Börjesson, P. Residual biomass as resource-Life-cycle environmental impact of wastes in circular resource systems. J. Clean. Prod. 2018, 196, 997-1006. [CrossRef]

6. D'Adamo, I. The Profitability of Residential Photovoltaic Systems. A New Scheme of Subsidies Based on the Price of CO2 in a Developed PV Market. Soc. Sci. 2018, 7, 148. [CrossRef]

7. United Nations Environment Programme (UNEP). Mobilizing Sustainable Finance for Small and Medium Sized Enterprises. 2017. Available online: http://www.minambiente.it/sites/default/files/ archivio_immagini/Galletti/G7/2_G7_env_unep_mobilizing_sustainable_finance_smes.pdf (accessed on 12 September 2018). 
8. Falcone, P.M. Green investment strategies and bank-firm relationship: A firm-level analysis. Econ. Bull. 2018, 38, 2225-2239.

9. Falcone, P.M.; Morone, P.; Sica, E. Greening of the financial system and fuelling a sustainability transition: A discursive approach to assess landscape pressures on the Italian financial system. Technol. Forecast. Soc. Chang. 2018, 127, 23-37. [CrossRef]

10. UNEP. The Financial System We Need: Aligning the Financial System with Sustainable Development. 2015a. Available online: http:/ / web.unep.org/inquiry/publications (accessed on 12 September 2018).

11. Polzin, F. Mobilizing private finance for low-carbon innovation: A systematic review of barriers and solutions. Renew. Sustain. Energy Rev. 2017, 77, 525-535. [CrossRef]

12. Hajer, M.A. Doing discourse analysis: Coalitions, practices, meaning. In Words Matter in Policy and Planning: Discourse Theory and Method in the Social Sciences; Van den Brink, M., Metze, T., Eds.; Netherlands Geographical Studies: Utrecht, The Netherlands, 2006.

13. Campiglio, E. Beyond carbon pricing: The role of banking and monetary policy in financing the transition to a low-carbon economy. Ecol. Econ. 2016, 121, 220-230. [CrossRef]

14. UNEP. Towards a Green Economy: Pathways to Sustainable Development and Poverty Eradication; United Nations Environment Programme: Nairobi, Kenya, 2011.

15. Della Croce, R.; Kaminker, C.; Stewart, F. The Role of Pension Funds in Financing Green Growth Initiatives; OECD Working Paper on Finance, Insurance and Private Pensions; Organization for Economic Co-Operation and Development: Paris, France, 2011.

16. United Nations Environment Programme Finance Initiative (UNEP FI). Green Paper on Financing a Global Deal on Climate Change. 2009. Available online: http:/ /ccsl.iccip.net/financing_global_deal.pdf (accessed on 12 September 2018).

17. Nakhooda, S.; Norman, M. Climate Finance-Is it Making a Difference? Overseas Development Institute: London, UK, 2014.

18. Höhne, N.; Khosla, S.; Fekete, H.; Gilbert, A. Mapping of Green Finance Delivered by IDFC Members in 2011; Ecofys: Cologne, Germany, 2012.

19. Zadek, S.; Flynn, C. South-Originating Green Finance: Exploring the Potential; The Geneva International Finance Dialogues, United Nations Environment Programme: Nairobi, Kenya, 2013.

20. Volz, U.; Böhnke, L.; Knierim, K.; Richert, K.; Röber, G.-M.; Eidt, V. Financing the Green Transformation: How to Make Green Finance Work in Indonesia; Palgrave Macmillan: Basingstoke, UK, 2015.

21. Pricewaterhouse Coopers Consultants (PWC). Exploring Green Finance Incentives in China; PWC: London, UK, 2013.

22. Buchner, B.K.; Heller, T.C.; Wilkinson, J. Effective Green Financing: What Have We Learned So Far? Climate Policy Initiative (CPI) Report; CPI: Venice, Italy, 2012.

23. Chaum, M.; Faris, C.; Wagner, G.; Buchner, B.; Falconer, A.; Trabacchi, C.; Brown, J.; Sierra, K. Improving the Effectiveness of Climate Finance: Key Lessons; Brookings: Washington, DC, USA, 2011.

24. Ticci, E.; Gabbi, G. Sustaining Sustainable Development: Re-thinking the Role of the Financial System. 2014. Available online: http:/ / www.congressi.unisi.it/fessudsiena/wp-content/uploads/sites/24/2014/ 04/Gabbi.pdf (accessed on 10 July 2018).

25. Ruppel, O.C.; Luedemann, C. Climate Finance: Mobilising Private Sector Finance for Mitigation and Adaptation; Institute for Security Studies: Pretoria, South Africa, 2013.

26. United Nations Environment Programme (UNEP). Aligning the Financial System with Sustainable Development. Pathways to Scale; Inquiry: Design of a Sustainable Financial System; UNEP: Nairobi, Kenya, 2015.

27. Romo, M. Investment decisions with financial constraints. Evidence from Spanish firms. Quant. Financ. 2014, 14, 1079-1095. [CrossRef]

28. Savignac, F. Impact of financial constraints on innovation: What can be learned from a direct measure? Econ. Innov. New Technol. J. 2008, 17, 553-569. [CrossRef]

29. Sica, E. Firms, Finance and Sustainable Transitions: The Financial Constraints of Eco-Innovation Companies; Edward Elgar: Cheltenham, UK, 2018.

30. García-Quevedo, J.; Segarra-Blasco, A.; Teruel, M. Financial constraints and the failure of innovation projects. Technol. Forecast. Soc. Chang. 2018, 127, 127-140. [CrossRef]

31. Mulkay, B.; Hall, B.H.; Mairesse, J. Firm level investment and R\&D in France and the United States. In Investing Today for the World of Tomorrow; Bundesbank, D., Ed.; Springer: Berlin, Germany, 2001. 
32. Bond, S.; Harhoff, D.; Van Reenen, J. Investment, RED, and Financial Constraints in Britain and in Germany'; IFS Working Paper No. 5; Institute for Fiscal Studies: London, UK, 1999.

33. Deng, K.; Ding, Z.; Zhu, Y.; Zhou, Q. Investment-cash flow sensitivity measures investment thirst, but not financial constraint. Account. Financ. 2017, 57, 165-197. [CrossRef]

34. Mancusi, M.L.; Vezzulli, A. R\&D and credit rationing in SMEs. Econ. Inq. 2014, 52, 1153-1172.

35. Mina, A.; Lahr, H.; Hughes, A. The demand and supply of external finance for innovative firms. Ind. Corp. Chang. 2013, 22, 869-901. [CrossRef]

36. Stockdale, B. UK Innovation Survey 2001. Econ. Trends 2002, 580, 36-42.

37. Silva, F.; Carreira, C. Do financial constraints threat the innovation process? Evidence from Portuguese firms. Econ. Innov. New Technol. 2012, 21, 701-736. [CrossRef]

38. Campello, M.; Graham, J.R.; Harvey, C.R. The real effects of financial constraints: Evidence from a financial crisis. J. Financ. Econ. 2010, 97, 470-487. [CrossRef]

39. Mohnen, P.; Palm, F.C.; Schim van der Loeff, S.; Tiwari, A. Financial constraints and other obstacles: Are they a threat to innovation activity? De Economist 2008, 156, 201-214. [CrossRef]

40. Francescato, V.; Negrin, M. The Cluster of Biomass Producers. Italian Best Practices and the Rule of Biomass Trade Centers for Ensuring Quality and Long-Term Supply. 2013. Available online: http:/ /www. congresobioenergia.org/ponencias/AIEL.pdf (accessed on 10 July 2018).

41. Pignatelli, V.; Alfano, V. Bioenergy Industry and Markets in Italy, ENEA. 2011. Available online: http: / / www.enea.it/it/internazionali/enea-in-japan-2011/energy/Pignatelli.pdf (accessed on 18 June 2018).

42. Noe, R.R.; Nachman, E.R.; Heavenrich, H.N.; Keeler, B.L.; Hernández, D.L. Assessing uncertainty in the profitability of prairie biomass production with ecosystem service compensation. Ecosyst. Serv. 2016, 21, 103-108. [CrossRef]

43. European Commission. Investment Plan. for Europe, COM (2014) 903 Final; European Commission: Brussels, Belgium, 2014.

44. European Commission. Contribution of the European Structural and Investment Funds to the 10 Commission Priorities: Energy Union and Climate Change; European Commission: Brussels, Belgium, 2015.

45. Wishlade, F.; Michie, R.; Vernon, P. Research for REGI Committee-Financial Instruments for Energy Efficiency and Renewable Energy; European Parliament, Policy Department for Structural and Cohesion Policies: Brussels, Belgium, 2017.

46. Rosenbloom, D.; Berton, H.; Meadowcroft, S. Framing the sun: A discursive approach to understanding multi-dimensional interactions within socio-technical transitions through the case of solar electricity in Ontario, Canada. Res. Policy 2016, 45, 1275-1290. [CrossRef]

47. Falcone, P.M.; Imbert, E. Social Life Cycle Approach as a Tool for Promoting the Market Uptake of Bio-Based Products from a Consumer Perspective. Sustainability 2018, 10, 1031. [CrossRef]

48. Provalis Research. QDA Miner Version 5.0 User Manual. Montreal, QC, Canada, 2011. Available online: https:/ / provalisresearch.com/uploads/QDA-Miner-5-User-Guide-V1.2.pdf (accessed on 10 July 2018).

49. Italian Report for the Social Impact Investment Task Force, 2015. Available online: http:// www.socialimpactinvestment.org/reports/Rapporto\%20Italiano\%20Ultima\%20versione.pdf (accessed on 10 July 2018).

50. Banca Etica. Social Balance Sheet. 2014. Available online: http://bilanciosociale.bancaetica.it/bilanciosociale-2014/ (accessed on 10 July 2018).

51. Vedogreen. IV Report Green Economy on Capital Markets. 2015. Available online: http:/ /www.vedogreen. it/osservatorio/20/osservatorio/ (accessed on 10 July 2018).

52. Deutsche Bundesbank. Green Finance: Risk and Opportunity. 2017. Available online: https:/ / www.bundesbank.de/Redaktion/EN/Standardartikel/Press/Contributions/2017_07_10_ dombret_handelsblatt_les_echos.html (accessed on 10 July 2018).

53. Clark, R.; Reed, J.; Sunderland, T. Bridging funding gaps for climate and sustainable development: Pitfalls, progress and potential of private finance. Land Use Policy 2018, 71, 335-346. [CrossRef]

54. Bowen, A.; Kuralbayeva, K. Looking for Green Jobs: The Impact of Green Growth on Employment, Global Green Growth Institute, Seoul (ROK). Available online: http://portal.gms-eoc.org/uploads/ resources/3382/attachment/Looking_for_green_jobs_the_impact_of_green_growth_on_employment_ GGGI_Grantham_Research_Institute_on_Climate_Change_on_the_Environment_0.pdf (accessed on 10 July 2018). 
55. Rosillo-Calle, F.; Woods, J. Overview of biomass energy. In The Biomass Assessment Handbook: Energy for a Sustainable Environment, 2nd ed.; Rosillo-Calle, F., de Groot, P., Hemstock, S.L., Woods, J., Eds.; Routledge: Abingdon, UK, 2015.

56. Guilhermino, A.; Lourinho, G.; Brito, P.; Almeida, N. Assessment of the use of forest biomass residues for bioenergy in Alto Alentejo, Portugal: Logistics, economic and financial perspectives. Waste Biomass Valorization 2018, 9, 739-753. [CrossRef]

57. Mazzucato, M.; Semieniuk, G. Financing renewable energy: Who is financing what and why it matters. Technol. Forecast. Soc. Chang. 2018, 127, 8-22. [CrossRef]

58. Mazzucato, M. From market fixing to market-creating: a new framework for innovation policy. Ind. Innov. 2016, 23, 140-156. [CrossRef]

59. Falcone, P.M. Analysing stakeholders' perspectives towards a socio-technical change: The energy transition journey in Gela Municipality. AIMS Energy 2018, 6, 645-657. [CrossRef]

2019 by the authors. Licensee MDPI, Basel, Switzerland. This article is an open access article distributed under the terms and conditions of the Creative Commons Attribution (CC BY) license (http:/ / creativecommons.org/licenses/by/4.0/). 